\title{
Pre-conception and prenatal factors influencing gestational weight gain: a prospective study in Tigray region, northern Ethiopia
}

Kebede Haile Misgina ${ }^{1,2^{*}}$, Eline M. van der Beek ${ }^{3}$, H. Marike Boezen ${ }^{2}$, Afework Mulugeta Bezabih ${ }^{4}$ and Henk Groen ${ }^{2}$

\begin{abstract}
Background: In low-income countries, the high prevalence of pre-pregnancy undernutrition remains a challenge for the future health of women and their offspring. On top of good nutrition, adequate gestational weight gain has been recognized as an essential prerequisite for optimal maternal and child health outcomes. However, good-quality data on factors influencing gestational weight gain is lacking. Therefore, this study was aimed to prospectively identify preconception and prenatal factors influencing gestational weight gain in Ethiopia.

Methods: A population based prospective study was undertaken between February 2018 and January 2019 in the Tigray region, northern Ethiopia. Firstly, the weight of non-pregnant women of reproductive age living in the study area was measured between August and October 2017. Subsequently, eligible pregnant women identified during the study period were included consecutively and followed until birth. Data were collected through an intervieweradministered questionnaire and anthropometric measurements complemented with secondary data. Gestational weight gain, i.e., the difference between 32 to 36 weeks of gestation and pre-pregnancy weights, was classified as per the Institute of Medicine (IOM) guideline. Linear, spline, and logistic regression models were used to estimate the influence of pre-conception and prenatal factors on gestational weight gain.

Results: The mean gestational weight gain (standard deviation[SD]) was 10.6 (2.3) kg. Overall, 64.0\% (95\% Cl 60.9, 67.1) of the women did not achieve adequate weight gain. Factors associated with higher gestational weight gain were higher women empowerment $(\mathrm{B} 0.60,95 \% \mathrm{Cl} 0.06,1.14)$, dietary diversity $(\mathrm{B} 0.39,95 \% \mathrm{Cl} 0.03,0.76)$, pre-pregnancy body mass index (B $0.13,95 \% \mathrm{Cl} 0.05,0.22)$, and haemoglobin ( $\mathrm{B} 0.54,95 \% \mathrm{Cl} 0.45,0.64)$. Additionally, adequate prenatal care (B $0.58,95 \% \mathrm{Cl} 0.28,0.88)$ was associated with higher gestational weight gain.

Conclusions: Adequate gestational weight gain was not achieved by most women in the study area, primarily not by those who were underweight before pregnancy. Interventions that advance women's empowerment, dietary quality, pre-pregnancy nutritional status, and prenatal care utilization may improve gestational weight gain and contribute to optimizing maternal and child health outcomes.
\end{abstract}

Keywords: Gestational weight gain, Socioeconomic factors, Body mass index, Ethiopia

\footnotetext{
*Correspondence: k.h.misgina@umcg.nl

2 Department of Epidemiology, University Medical Center Groningen,

University of Groningen, Groningen, The Netherlands

Full list of author information is available at the end of the article
} original author(s) and the source, provide a link to the Creative Commons licence, and indicate if changes were made. The images or other third party material in this article are included in the article's Creative Commons licence, unless indicated otherwise in a credit line to the material. If material is not included in the article's Creative Commons licence and your intended use is not permitted by statutory regulation or exceeds the permitted use, you will need to obtain permission directly from the copyright holder. To view a copy of this licence, visit http://creativecommons.org/licenses/by/4.0/. The Creative Commons Public Domain Dedication waiver (http://creativeco mmons.org/publicdomain/zero/1.0/) applies to the data made available in this article, unless otherwise stated in a credit line to the data. 


\section{Background}

Weight gain during pregnancy, which is attributed to several physiologic changes, is normal. The physiologic changes include an increase in uterus's size to accommodate the growing fetus, amniotic fluid, and placenta. Additionally, breasts enlarge, and blood and interstitial fluid volume rise. These changes contribute to increased weight, as do increased cellular water and maternal reserves [1, 2]. Adequate gestational weight gain, i.e., weight gain within the range recommended by the 2009 U.S. Institute of Medicine (IOM) guideline, is essential to gratify the metabolic demands of the women and their unborn children. Thereby, it could contribute to optimizing maternal and neonatal outcomes [2]. Examining the effects of weight gain across a range of pre-pregnancy body mass indices (BMI), the IOM guideline recommends that a weight gain of $12.5-18.0 \mathrm{~kg}$ for underweight, $11.5-16.0 \mathrm{~kg}$ for normal weight, $7.0-11.0 \mathrm{~kg}$ for overweight, and $5.0-9.0 \mathrm{~kg}$ for obese women. Inadequate weight gain or weight gain below the lower cut-offs has been shown to cause adverse maternal [3] and birth outcomes [3-10]. The adverse birth outcomes include preterm birth and low birth weight. Such adverse birth outcomes increase the risk of child mortality. For survivors, the adverse birth outcomes have negative consequences extending from early childhood across the life course and subsequent generations $[3,8,11]$.

In low-income settings, where maternal undernutrition is common, inadequate gestational weight gain is also rampant [12-17]. According to a recent meta-analysis $>58 \%$ of women gained inadequate weight in subSaharan Africa including Ethiopia. Among underweight women, inadequate gestational weight gain ranged from 67.0 to $98.0 \%[12,18]$. Given the high prevalence of prepregnancy undernutrition [19], the omnipresent inadequate gestational weight gain remains a challenge for the future health of women as well as their offspring, perpetuating the cross-generational effects of chronic undernutrition in early life.

Different environmental and lifestyle factors may contribute to the actual gestational weight gain. These factors may include socioeconomic conditions [12], pregnancy plan, physical activity $[2,12]$, dietary practice [20], prepregnancy body mass index [18], distress [21, 22], and prenatal care [18]. However, the factors may vary with context $[2,12]$. Most of the previous studies were from developed countries where adverse outcomes attributed to undernutrition are not prevalent. Besides, the limited numbers of studies in low-income settings were not or partially controlled for relevant confounders $[4,12]$. Cognizant of this, factors influencing gestational weight gain are inconsistent and inconclusive. Furthermore, almost all studies in low-income settings relied on women's recall of their pre-pregnancy weight or weight measured at prenatal care booking as a proxy for pre-pregnancy weight. In low-income settings, women hardly keep track of their body weight and often delay their prenatal care booking until the second trimester. As a result, the data are subjected to bias [12].

Therefore, there is a lack of good-quality data concerning gestational weight gain in low-income settings [12]. Such evidence is required to determine how adequate nutrition during the pre-pregnancy and pregnancy period can be used as a window of opportunity to improve maternal and child health. Such improvements could benefit the next generation in preventing the crossgenerational perpetuation of chronic undernutrition. Thus, the present study was aimed to prospectively identify pre-conception and prenatal factors influencing gestational weight gain in Ethiopia.

\section{Methods}

\section{Study design, setting, and population}

The analyses for this study were performed on data from the KIlte-Awlaelo Tigray Ethiopia (KITE) cohort, a prospective cohort study in Kilite-Awlaelo Health and Demographic Surveillance Site (KA-HDSS) conducted between February 2018 and January 2019 [23]. KA-HDSS is located in the eastern zone of the Tigray region, northern Ethiopia. The site has 113,760 residents in ten rural and three urban kebeles (the smallest administrative units). Women of reproductive age account for $24 \%$ of the population. Within the surveillance site, about 4550 pregnancies are expected per year. Most of the population live in rural settings, and agriculture is the primary source of income.

Ethiopia has a three-tier health care system with health posts at the forefront of primary care. There is one health post in each kebele staffed by two to three Health Extension Workers (HEWs). Health posts provide promotional and preventive services under the umbrella of the thealth extension package.' The primary delivery modality of the package is through home-to-home visits. The health extension package consists of 16 components concerning family health services, disease prevention and control, and hygiene and environmental sanitation. The components include maternal and child health, family planning, nutrition, proper and safe waste disposal, and food hygiene and safety measures. Health Extension Workers train the households in their catchment area on health extension package and follow the progress of implementing the package after the training [24].

The sample size was calculated to achieve the objectives of the prospective study with respect to pregnancy outcomes in relation to nutritional status. The primary outcome was low birth weight, and the target was to be 
able to discriminate an estimated proportion of $24.6 \%$ low birth weight among women with Mid-Upper Arm Circumference (MUAC) $\geq 23.0 \mathrm{~cm}$ and a proportion of $32.6 \%$ among women with MUAC $<23.0 \mathrm{~cm}$, as a cutoff to define undernutrition [25], with an alpha of $5 \%$ (2-sided), $80 \%$ power, and a $10 \%$ drop-out rate. The total sample size was calculated at 1100 . With this sample size, differences in continuous outcomes $>0.2$ standard deviations (SD) could also be detected.

Firstly, the weight of non-pregnant women $(n=17,500)$ living in the study area was measured between August and October 2017 using a Seca scale to the nearest $100 \mathrm{~g}$. Subsequently, eligible pregnant women were identified and included consecutively between February 2018 and January 2019. A community-based survey by Health Extension Workers through the "Women Development Army," a network of health information workers reaching individual households around the health posts, was applied to identify the pregnant women. Also, antenatal records and the KA-HDSS database were used to identify pregnant women. The criteria for inclusion were being married, being aged 18 or over, having weight measured before pregnancy, and having completed $\leq 20$ weeks of gestation.

Identifying unmarried pregnant women is complicated by lack of registration that is also required to facilitate follow-up. In the study area, identification of women is based on identifying their respective households, which requires knowing the name of the household head (the husband). Therefore, only married women were included in the study, which was also an opportunity to collect husband information. As height continues to increase during the adolescence period, women aged $<18$ were excluded to minimize bias in nutritional data.

\section{Measurements}

An interviewer-administered questionnaire and anthropometric measurements were used to collect the data. Additionally, secondary data were extracted from the KA-HDSS database and antenatal records. The questionnaire was adapted from the literature [18, 25-29] and was pretested on a convenience sample of 55 pregnant women in Tahtay-Maichew, the central zone of the Tigray region. Qualified Health Extension Workers collected the data. The detailed descriptions of the measurements at different time points are provided below.

\section{At inclusion (at $\leq \mathbf{2 0}$ weeks of gestation)}

Age, residence (urban or rural), religion (Orthodox, Catholic, Muslim or others), educational status (no formal education, primary education, or secondary and above education), occupation (farmer, housewife or others), household size, and economic status were extracted from the KA-DHSS database. The database is updated every six months except for the economic status. For socioeconomic proxy indicator variables, adjustments were made at inclusion when there was a change since the last update. Then, economic status was determined by generating wealth index quintiles designating the lowest to the highest economic status from the proxy indicators. The socioeconomic proxy indicator variables included housing characteristics, access to improved water and sanitation facilities, and ownership of household assets, land, and livestock [30].

Access to improved drinking water sources refers to access to piped water on-premises, public taps or standpipes, tube wells or boreholes, protected dug wells, protected springs, and/or rainwater collection. Similarly, access to an improved sanitation facility was defined as access to an unshared toilet facility, pit latrine with a slab, ventilated improved pit latrine, or flush toilet [31]. Besides access, the time needed to fetch improved drinking water from the nearest source was collected at inclusion. Then, the self-reported time was dichotomized at a cut-off point of $30 \mathrm{~min}$, with the time needed not exceeding $30 \mathrm{~min}$ indicating better service [31].

Moreover, access to the health facility was measured at inclusion by asking 'How long does it take to go to the nearby health facility and back home?' To assess the implementation of the health extension package, data were collected at inclusion by checking if the women's respective households were certified as model households or not. Model household is a proxy for implementing the health extension package described above. For a household to be certified as a model, the requirement is receiving short-term training on the health extension package and implementing the package after the training [24]. Additionally, a short form of the International Physical Activity Questionnaire (IPAQ) was used to measure physical activity at inclusion, and the data were summarized as per the scoring protocol [29, 32]. Self-reported history of pre-pregnancy illnesses and perceived work burden were also collected at inclusion. Work burden was rated as easy, moderate, or difficult.

As part of the assessment of reproductive characteristics, the number of previous pregnancies, parity, history of abortion, and history of stillbirth, were extracted from the KA-DHSS database. Other reproductive factors like age at first marriage, age at first birth, a previous interbirth interval in months, and history of preterm birth, delivery by $\mathrm{C}$-section, and severe perinatal hemorrhage were collected by interview at inclusion. Based on this information, a history of adverse pregnancy outcomes was defined as having experienced one or more of the following: abortion, stillbirth, preterm birth, severe perinatal hemorrhage, or delivery by $\mathrm{C}$-section. 
Women were also asked to report on the four-item HITS (Hurt, Insult, Threaten, and Scream) scale at inclusion to assess intimate partner violence. Each question was scored from 1 to 5 , and a total score $>10$ was used as suggestive of violence [33]. Similarly, women's empowerment was assessed by asking nine questions addressing three dimensions of empowerment: economic, socio-familial, and legal. The economic empowerment asked the relative income to husband, control over men's income, control over women's income, and decisionmaking on large household purchases. Likewise, the socio-familial empowerment was scored based on decision-making on family visits, decision-making on women's health and attitude towards domestic violence. In contrast, the legal empowerment assessed women's legal entitlements over land and house [34-36]. Then, coding each as 1 or 0 , the scores were totaled as women empowerment scores (0 to 9). Furthermore, the question "At the time you became pregnant, did you wanted to get pregnant then, wanted later, or did not want at all?" was asked at inclusion to assess the index pregnancy plan. Accordingly, if the intention was not to get pregnant then, the pregnancy was considered unplanned.

Food and dietary characteristics, including the number of meals per day, frequency of dietary intake (vegetables, fruits, animals-source food, alcohol, and coffee), fasting, agrobiodiversity, harvest volume, dietary diversity, and food security, were assessed at inclusion. In assessing fasting, women were asked, 'Do you fast?'. If you fast, 'Which one: the regular weekly fast, the long fast times, or both?' The weekly fast includes fasting every Wednesday and Friday almost throughout the year. The longer fasting periods include the 40-days Christmas fast, the 55-days of Lenten, the 14-days Apostles fast, and the14days Dormition fast. Women were regarded as 'fasting' if they fasted both the weekly and the long fasting times.

Agrobiodiversity was captured by querying women about a list of food crops and livestock products their households produced in the past year. Then, by counting the number of product groups consisting cereals, roots, and tubers; legumes and nuts; oilseeds; fruits; vegetables; dairy; egg; and meat and poultry, a sum score of agrobiodiversity ranging from 0 to 8 was obtained [37]. Additionally, the amount of produce of each crop, expressed in quintiles was asked, and total harvest volume was calculated by adding the amounts reported for all crops.

A 24-h dietary diversity score was obtained by asking women if they consumed a list of food groups with 'yes' or 'no' response options. The sum yielded a dietary diversity score ranging from 0 to 10 , with scores $\geq 5$ indicating adequate diet diversity [27]. Moreover, to measure household food insecurity, women were asked how often nine specific food insecurity associated conditions, if any, happened in the previous month (0) not at all, 1) rarely, 2) sometimes, or 3) often) [28]. The answers were aggregated to a food insecurity score between 0 and 27 . If the responses to all occurrence questions were no or if the affirmative response was only to "did you worry that your household would not have enough food" in a rare frequency of occurrence, households were classified as food secure [28].

Partner support was rated by the five-item Turner Support Scale with each item scored from 0 to 3 [38], and a sum score $<10$ was defined as low. Support from significant other social sources was also rated using Oslo-3 Social Support Scale, and scoring $\leq 8$ was considered low [39]. Both were summed up as a total support score. Distress was obtained using the ten-item Edinburgh Postnatal Depression Scale [40], the seven-item anxiety subscale of the Hospital Anxiety and Depression Scale [41], and the four-item Perceived Stress Scale [42]. The depression and anxiety scales were rated from 0 to 3 , while the stress scale was scored from 0 to 4 . Summing the standardized depression, anxiety, and stress scores, a total distress score was obtained. Additionally, a cut-off point $\geq 13$ as suggestive of high depressive symptoms [40] and $\geq 8$ for high symptoms of anxiety and stress were used. To indicate the level of distress, the presence of high symptoms in one, two, or all of the three domains, i.e., anxiety, depression, or stress, were considered.

Anthropometric measures; weight to the nearest $100 \mathrm{~g}$ as measured before pregnancy, and height to the nearest $0.1 \mathrm{~cm}$ were collected at inclusion using a Seca scale and height-measuring board. Likewise, MUAC to the nearest $0.1 \mathrm{~cm}$ was measured using MUAC-measuring tape. All measurements were taken twice and averaged. Pre-pregnancy BMI (pre-pregnancy weight $(\mathrm{kg}) /[\text { height }(\mathrm{m})]^{2}$ ) was categorized as underweight $(\mathrm{BMI}<18.5)$, normal weight (BMI $=18.5$ to 24.9 ), or overweight (BMI $\geq 25.0$ ), and so was BMI calculated from weight and height measured at inclusion. MUAC below $21.0 \mathrm{~cm}$ was defined as undernutrition [43].

\section{In the third trimester ( 32 to 36 weeks)}

At this stage, data on self-reported stressful life events that occurred in the past year, attendance of prenatal care, illness during pregnancy, and pregnancy complications were obtained [44]. Prenatal care was defined as adequate plus (five or more visits), adequate (four visits), or intermediate (two or three visits) for women who began prenatal care at $\leq 16$ weeks of gestation. Prenatal care was defined as inadequate if started at $>16$ weeks or was received only once [45].

Moreover, weight and MUAC were measured as they were measured at inclusion. Also, data on human immunodeficiency virus (HIV) infection, urine analysis, 
rhesus factor, stool examination, venereal diseases, hepatitis B infection, haemoglobin, and other illnesses were extracted from antenatal records when available. Based on the measures at prenatal care booking, haemoglobin $<11 \mathrm{~g} / \mathrm{dL}$ was defined as anaemia.

\section{Statistical analysis}

Data were entered into Epi-Data 3.1 and analyzed with STATA (Version 11, Stata Corporation, College Station, Texas, USA). Proportions and means (SD) or medians (interquartile range [IQRs]) were used to describe the characteristics of the study population. Gestational weight gain, obtained by subtracting pre-pregnancy weight from weight measured between 32 to 36 weeks of gestation, was classified based on the 2009 IOM guideline. As excessive weight gain was rare, weight gain was re-categorized into inadequate or adequate. Student's t-test or Mann Whitney U-test, as appropriate, was used to comparing the mean of continuous variables between women with adequate and inadequate weight gain. To compare the distribution of categorical variables by adequacy of weight gain, a Chi-squared test was used.

The assumption of linear association between gestational weight gain and the independent variables was preliminarily tested with ANOVA comparing mean weight gain by categories of each independent variable. If this test suggested non-linearity, spline regression was applied (Stata adjust-rcspline package), and each independent variable was partitioned into two continuous variables, below and above the knot value $(\mathrm{K})$, using the mkspline command [46]. The coefficient $B_{2}$ for the second spline variable represents the change in the effect of the variable above $\mathrm{K}$ as compared to below $\mathrm{K}$. The effect of a unit increase in the value of the variable above $K$ can be obtained as $B_{2}-B_{1}$, where $B_{1}$ is the coefficient of the lower partition. The knot value resulting in the best-fitted linear spline regression model, as apparent by the lowest root mean square of errors, was determined by checking the different values of the respective independent variable around a knot value estimated by viewing the linear spline regression curves. Finally, the two variables with their intercepts were regressed against gestational weight gain. If the coefficient for the second spline variable was statistically significant, this was considered to indicate that the effect of values above the knot was significantly different from below the knot, and we concluded that the association was non-linear. When the linear spline regression fitted better than quadratic and cubic models, the two variables and the second intercept were included in the analysis.

The unadjusted association of the independent variables with gestational weight gain was assessed using univariable linear regression. Including all statistically significant independent variables $(P<0.05$, tested twosided) from the univariable analyses, a multivariable linear regression model was fitted to determine adjusted effects on gestational weight gain. The normality of residuals was assessed through the normal probability and quantile-quantile plots. Homogeneity of variance was checked using the Breusch-Pagan test. Moreover, the model specification and omitted variable bias were tested using the Stata linktest and ovtest commands. Also, multicollinearity was assessed using the variance inflation factor (vif).

Finally, the probability of achieving adequate gestational weight gain by optimizing the foremost factors was estimated based on a multivariable logistic regression model using marginal standardization [47]. All independent variables that were significantly associated with adequate gestational weight gain $(P<0.05$, tested two-sided) in the univariable analyses were included in the subsequent multivariable logistic regression model. Residence and MUAC were correlated with other variables and were not included.

\section{Results}

Of the 991 pregnant women included at a mean (SD) of 14.8 (1.9) weeks of gestation, 934 were followed and their weight measured between 32 to 36 weeks of gestation (mean $[\mathrm{SD}]=33.9$ [1.1] weeks). Table 1 summarizes the nutritional characteristics of the women by gestational weight gain. Before pregnancy, their average weight (SD) was 49.0 (6.6) $\mathrm{kg}$ with a respective BMI of $19.7(2.0)$ $\mathrm{kg} / \mathrm{m}^{2}$. The mean weight (SD) gained at inclusion was $2.4(1.0) \mathrm{kg}$ and $10.6(2.3) \mathrm{kg}$ at 32 to 36 weeks of gestation. Figure 1 provides weight gain by MUAC and BMI. Overall, 64.0\% (95\% CI 60.9, 67.1) of the women did not achieve adequate weight gain, with the prevalence being 91.6\% among underweight women. On the other side of the gestational weight gain spectrum, $0.4 \%$ (95\% CI 0.2, 1.1) of the women gained excessive weight.

Socioeconomic characteristics are shown in Table 2. At inclusion, the women's average age (SD) was 29.3 (6.5), slightly more than a third (35\%) were urban dwellers, 338 (36.2\%) had no formal education, and a large majority $(88.5 \%)$ were housewives or farmers. Significant differences between women with adequate and inadequate weight gain were seen in residence, family size, model household, physical activity, distress, and support from social sources $(P<0.05)$.

As shown in Table 3, the mean (SD) parity among the non-nulliparous women was 3.3 (2.1). With 379 $(40.6 \%)$ of the index pregnancies being unplanned, 437 (46.8\%) women did not have adequate prenatal care, and $210(22.5 \%)$ had a history of illness during the pregnancy. As to the food and dietary characteristics, many 
Table 1 Summary of nutritional characteristics of women $(n=934)$ by gestational weight gain, northern Ethiopia, 2018

\begin{tabular}{|c|c|c|c|c|c|c|c|c|}
\hline \multirow[t]{3}{*}{ Characteristics } & \multicolumn{6}{|c|}{ Gestational weight gain classification based on IOM recommendations } & \multirow{2}{*}{\multicolumn{2}{|c|}{ Total $(n=934)$}} \\
\hline & \multicolumn{2}{|c|}{ Inadequate $(n=598)$} & \multicolumn{2}{|c|}{ Adequate $(n=332)$} & \multicolumn{2}{|c|}{ Excessive $(n=4)$} & & \\
\hline & Mean (SD) & Range & Mean (SD) & Range & Mean (SD) & Range & Mean (SD) & Range \\
\hline Height, cm & $157.4(0.1)$ & 135.2 to 175.8 & $157.6(0.1)$ & 132.6 to 181.2 & $154.4(0.0)$ & 150.4 to 160.6 & $157.4(0.1)$ & 132.6 to 181.2 \\
\hline Pre-pregnancy weight, kg & $47.5(6.4)$ & 31.8 to 68.9 & $51.7(6.2)$ & 33.3 to 72.9 & $57.0(7.7)$ & 47.9 to 66.1 & $49.0(6.6)$ & 31.8 to 72.9 \\
\hline Pre-pregnancy BMI, kg/m² & $19.1(1.9)$ & 15.0 to 25.4 & $20.8(1.7)$ & 15.8 to 25.3 & $23.8(2.2)$ & 21.20 to 25.6 & $19.7(2.0)$ & 15.0 to 25.7 \\
\hline MUAC at inclusion, $\mathrm{cm}$ & $22.0(1.9)$ & 17.5 to 29.3 & $23.6(1.7)$ & 18.1 to 28.3 & $26.6(2.4)$ & 23.8 to 29.6 & $22.6(2.0)$ & 17.5 to 29.3 \\
\hline Weight at inclusion, $\mathrm{kg}$ & $49.6(6.4)$ & 34.2 to 71.5 & $54.6(6.3)$ & 36.6 to 75.7 & $60.0(8.9)$ & 49.5 to 70.9 & $51.5(6.9)$ & 34.2 to 75.7 \\
\hline $\begin{array}{l}\text { Weight gain at inclusion, } \mathrm{kg} \\
(n=933)\end{array}$ & $2.15(0.9)$ & 0.6 to 5.3 & $2.9(1.1)$ & 1.2 to 6.4 & $3.1(1.3)$ & 1.6 to 4.8 & $2.4(1.0)$ & 0.6 to 6.4 \\
\hline BMl at inclusion, $\mathrm{kg} / \mathrm{m}^{2}$ & $20.0(1.9)$ & 16.2 to 26.2 & $21.9(1.7)$ & 17.3 to 26.1 & $25.1(2.6)$ & 21.9 to 27.5 & $20.7(2.1)$ & 16.2 to 27.5 \\
\hline MUAC at 32 to 36 weeks, cm & $22.2(1.9)$ & 17.8 to 29.3 & $23.8(1.6)$ & 18.3 to 28.3 & $26.8(2.3)$ & 24.20 to 29.8 & $22.8(2.0)$ & 17.8 to 29.8 \\
\hline Weight at 32 to 36 weeks, $\mathrm{kg}$ & $56.8(6.7)$ & 39.7 to 78.8 & $64.6(6.3)$ & 44.9 to 88.3 & $73.3(7.8)$ & 64.3 to 83.1 & $59.6(7.6)$ & 39.7 to 88.3 \\
\hline Gestational weight gain, kg & $9.3(1.6)$ & 5.0 to 14.8 & $13.0(1.2)$ & 8.7 to 17.0 & $16.4(0.8)$ & 15.3 to 17.0 & $10.6(2.3)$ & 5.0 to 17.0 \\
\hline
\end{tabular}

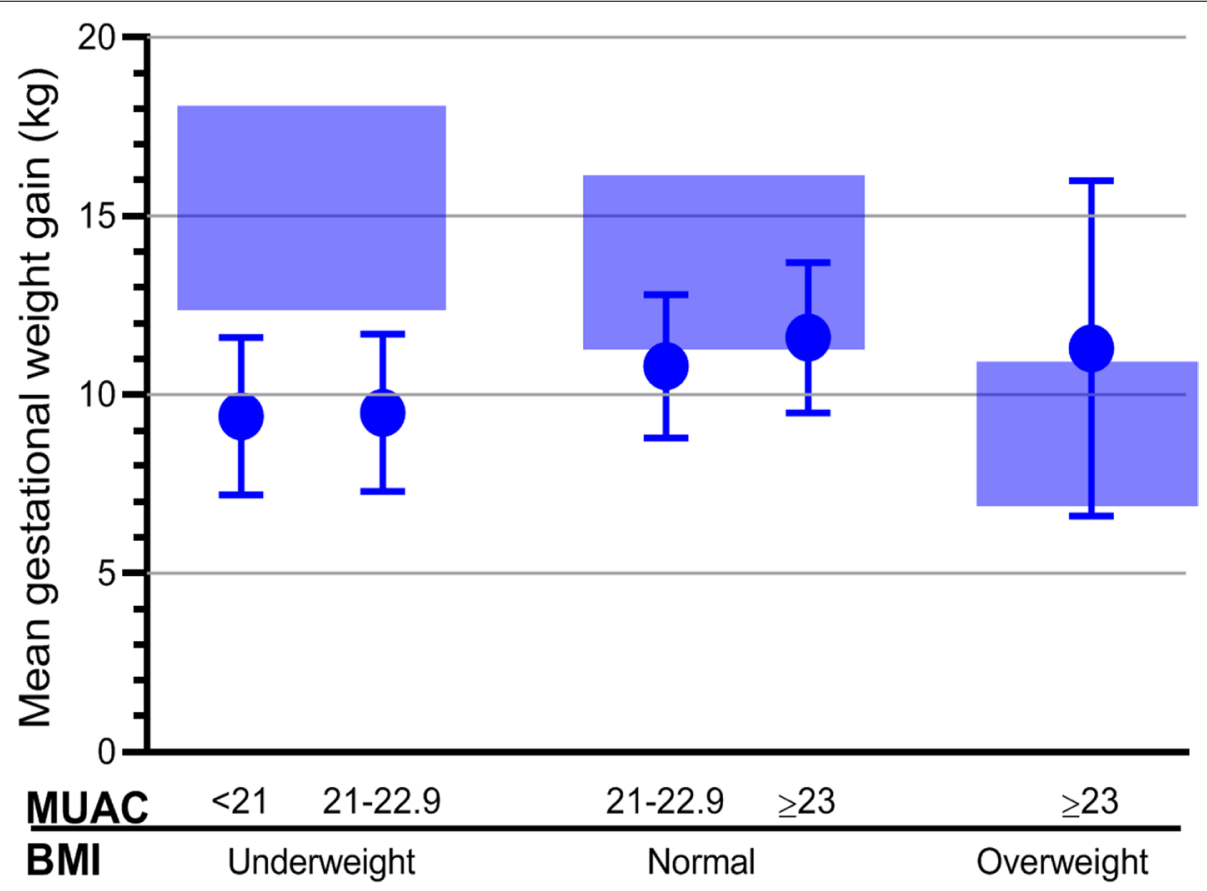

Fig. 1 Average gestational weight gain by pre-pregnancy BMI (underweight: BMI<18.5 ( $n=335)$; Normal: BMl 18.5-25.0 ( $n=594)$; overweight: $\mathrm{BMI} \geq 25.0(n=5))$ and by MUAC $(<21.0 \mathrm{~cm}$ versus $22.0-22.9 \mathrm{~cm}$ versus $\geq 23.0 \mathrm{~cm})$ compared to the $1 \mathrm{OM}$ recommended range of weight gain as shown by the blue shaded boxes, northern Ethiopia, 2018. Error bars indicate SD

women (38.7\%) belonged to food-insecure households, and the diversity of their diet was inadequate $(47.2 \%)$. Significant differences were observed between women with inadequate and adequate weight gain in women empowerment, intimate partner violence, prenatal care, haemoglobin, diet diversity, food insecurity, and agrobiodiversity $(P<0.05)$.
The results of multivariable linear regression analysis are depicted in Table 4. Excluding women with missing data, 882 were included in the final analysis. Women excluded from the final analysis did not differ from the remainder in all aspects except in residence and occupation. The difference in occupation was no longer significant after stratifying by residence (Additional file 1). 
Table 2 Socioeconomic characteristics of women by gestational weight gain, northern Ethiopia, 2018

\begin{tabular}{|c|c|c|c|c|}
\hline \multirow[t]{2}{*}{ Characteristic } & \multirow{2}{*}{ Total, $n=934$} & \multicolumn{2}{|c|}{ Gestational weight gain } & \multirow[t]{2}{*}{$P$-value } \\
\hline & & Adequate, $n=336$ & Inadequate, $n=598$ & \\
\hline Age in year, mean (SD) & $29.3(6.5)$ & $29.1(6.4)$ & $29.4(6.6)$ & .376 \\
\hline Rural residence, $n(\%)$ & $607(65.0)$ & $202(60.1)$ & $403(67.4)$ & .031 \\
\hline Religion, n (\%) & & & & .764 \\
\hline Orthodox & $922(98.7)$ & $331(98.5)$ & $591(98.8)$ & \\
\hline Others (Muslim and Catholic) & $12(1.3)$ & $5(1.5)$ & $7(1.2)$ & \\
\hline Educational status of the woman, $n(\%)$ & & & & .700 \\
\hline No formal education & $338(36.2)$ & $120(35.7)$ & $218(36.5)$ & \\
\hline Primary education & $307(32.9)$ & $109(32.4)$ & $198(33.1)$ & \\
\hline Secondary education or above & $289(30.9)$ & $107(31.9)$ & $182(30.4)$ & \\
\hline Occupation of woman, $\mathrm{n}(\%)$ & & & & $.158^{\mathrm{a}}$ \\
\hline Farmer & $506(54.1)$ & $168(50.0)$ & $338(56.5)$ & \\
\hline Housewife & $321(34.4)$ & $126(37.5)$ & $195(32.6)$ & \\
\hline Employed & $85(9.1)$ & $39(11.6)$ & $46(6.7)$ & \\
\hline Others $^{b}$ & $22(2.4)$ & $3(0.9)$ & $19(3.2)$ & \\
\hline Educational status of husband, $\mathrm{n}(\%)$ & & & & .495 \\
\hline No formal education & $300(32.1)$ & $104(31.0)$ & $196(32.8)$ & \\
\hline Primary education & $345(36.9)$ & $124(36.9)$ & $221(37.0)$ & \\
\hline Secondary education or above & $289(31.0)$ & $108(32.1)$ & $181(30.2)$ & \\
\hline Occupation of husband, $\mathrm{n}(\%)$ & & & & .073 \\
\hline Farmer & $484(51.8)$ & $157(46.7)$ & $327(54.7)$ & \\
\hline Employed & $212(22.7)$ & $83(24.7)$ & $129(21.6)$ & \\
\hline Daily laborer & $148(15.9)$ & $64(19.1)$ & $84(14.0)$ & \\
\hline Others ${ }^{c}$ & $90(9.6)$ & $32(9.5)$ & $58(9.7)$ & \\
\hline Household size, mean (SD) & $4.5(2.0)$ & $4.6(2.1)$ & $4.3(1.9)$ & .042 \\
\hline Model household, $\mathrm{n}(\%)$ & $229(24.5)$ & $101(30.1)$ & $128(21.4)$ & .004 \\
\hline Access to health facility in minutes, median (IQR) & $32.5(25-75)$ & $40(25-80)$ & $30(20-70)$ & $.070^{d}$ \\
\hline Access to improved source of water, $n(\%)$ & $835(89.4)$ & $302(89.9)$ & $533(89.1)$ & .805 \\
\hline Time needed to fetch water not exceed $30 \mathrm{~min}, \mathrm{n}(\%)$ & $745(79.8)$ & $266(79.2)$ & $479(80.1)$ & .734 \\
\hline Access to improved sanitation facility, $n$ (\%) & $132(14.1)$ & $46(13.7)$ & $86(14.4)$ & .847 \\
\hline Household own $<0.5$ ha farmland, $\mathrm{n}(\%)$ & $635(68.0)$ & $232(69.0)$ & $403(67.4)$ & .654 \\
\hline Wealth index, n (\%) & & & & .483 \\
\hline Poorest & $189(20.2)$ & $67(20.0)$ & $122(20.4)$ & \\
\hline Second poor & $185(19.8)$ & $70(20.8)$ & $115(19.2)$ & \\
\hline Middle & $190(20.3)$ & $73(21.7)$ & $117(19.6)$ & \\
\hline Second rich & $186(20.0)$ & $70(20.8)$ & $116(19.4)$ & \\
\hline Rich & $184(19.7)$ & $56(16.7)$ & $128(21.4)$ & \\
\hline Physical activity, n (\%) & & & & $<.001$ \\
\hline Low & $497(53.2)$ & $208(61.9)$ & $289(48.3)$ & \\
\hline Moderate & $404(43.3)$ & $122(36.3)$ & $282(47.2)$ & \\
\hline High & $33(3.5)$ & $6(1.8)$ & $27(4.5)$ & \\
\hline \multicolumn{5}{|l|}{ Perceived work burden, $\mathrm{n}(\%)$} \\
\hline Easy & $383(41.0)$ & $146(43.4)$ & $237(39.6)$ & .407 \\
\hline Moderate & $414(44.3)$ & $141(42.0)$ & $273(45.7)$ & \\
\hline Difficult & $137(14.7)$ & $49(14.6)$ & $88(14.7)$ & \\
\hline Low support from partner and others, $n$ (\%) & $72(7.7)$ & $17(5.1)$ & $55(9.2)$ & $<.001$ \\
\hline At least one stressful life event, $n(\%)$ & $343(36.7)$ & $104(30.9)$ & $239(40.0)$ & .002 \\
\hline Distress, n (\%) & & & & .006 \\
\hline Not distressed at all & $518(55.5)$ & $207(61.6)$ & $311(52.0)$ & \\
\hline Distressed in one domain & $206(22.1)$ & $75(22.3)$ & $131(21.9)$ & \\
\hline Distressed in two domains & $122(13.0)$ & $36(10.7)$ & $86(14.4)$ & \\
\hline Distressed in three domains & $88(9.4)$ & $18(5.4)$ & $70(11.7)$ & \\
\hline History of pre-pregnancy illness, n (\%) & $128(13.7)$ & $41(12.2)$ & $87(14.5)$ & .317 \\
\hline
\end{tabular}

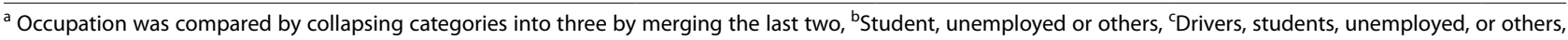
and ${ }^{\mathrm{d}}$ Mann-Whitney U-test 
Table 3 Reproductive and obstetric conditions as well as food and dietary characteristics of the participating women by gestational weight gain, northern Ethiopia, 2018

\begin{tabular}{|c|c|c|c|c|}
\hline \multirow[t]{2}{*}{ Reproductive and obstetric conditions } & \multirow[t]{2}{*}{ Total, $n=934$} & \multicolumn{2}{|c|}{ Gestational weight gain } & \multirow[t]{2}{*}{$P$-value } \\
\hline & & Adequate, $n=336$ & Inadequate, $n=598$ & \\
\hline Age at first marriage in year, median (IQR) & $18(17-20)$ & $18(17-20)$ & $18(17-20)$ & $.131^{\mathrm{a}}$ \\
\hline Nulliparous before the index pregnancy, n (\%) & $181(19.4)$ & $112(18.7)$ & $69(20.5)$ & .559 \\
\hline Parity $(n=753)$, mean (SD) & $3.3(2.1)$ & $3.9(1.8)$ & $4.1(1.9)$ & .113 \\
\hline Age at first birth in year ( $n=747)$, median (IQR) & $19(18-21)$ & $19(18-21)$ & $19(18-20)$ & $.176^{\mathrm{a}}$ \\
\hline Previous birth interval in months $(n=558)$, median (IQR) & $38(30-48)$ & $39(33-48)$ & $37(30-47)$ & $.085^{\mathrm{a}}$ \\
\hline History of adverse birth outcome, n (\%) & $187(24.8)$ & $65(19.3)$ & $122(20.4)$ & .887 \\
\hline Ever used modern contraceptive, n (\%) & $725(77.6)$ & $262(78.0)$ & $463(77.4)$ & .911 \\
\hline Women empowerment score, mean (SD) & $5.6(1.5)$ & $5.9(1.5)$ & $5.4(1.4)$ & $<.001$ \\
\hline Intimate partner violence score, mean (SD) & $6.9(3.0)$ & $6.2(2.6)$ & $7.3(3.1)$ & $<.001$ \\
\hline Unplanned index pregnancy, n (\%) & $379(40.6)$ & $122(36.3)$ & $257(43.0)$ & .055 \\
\hline Adequacy of prenatal care utilization, $n(\%)$ & & & & .006 \\
\hline Inadequate & $385(41.2)$ & $114(33.9)$ & $271(45.3)$ & \\
\hline Intermediate & $112(12.0)$ & $41(12.2)$ & $71(11.9)$ & \\
\hline Adequate & $380(40.7)$ & $156(46.4)$ & $224(37.5)$ & \\
\hline Adequate plus & $57(6.1)$ & $25(7.5)$ & $32(5.3)$ & \\
\hline Iron-folic-acid tablets taken in two weeks, mean (SD) & $10.2(3.6)$ & $10.6(3.2)$ & $10.4(3.2)$ & .218 \\
\hline Haemoglobin $(n=882)$, mean (SD) & $11.9(1.6)$ & $12.9(1.3)$ & $11.4(1.5)$ & $<.001$ \\
\hline Anaemic $(n=882), \mathrm{n}(\%)$ & $271(30.7)$ & $24(7.5)$ & $247(43.8)$ & $<.001$ \\
\hline Number of pregnancy complications, median (IQR) & $1(0-2)$ & $1(0-2)$ & $1(0-2)$ & $.177^{\mathrm{a}}$ \\
\hline Number of pregnancy complications, n (\%) & & & & .098 \\
\hline None & $428(45.8)$ & $139(41.4)$ & $289(48.3)$ & \\
\hline One & $335(17.6)$ & $67(19.9)$ & $97(16.2)$ & \\
\hline Two or more & $342(36.6)$ & $130(38.7)$ & $212(35.5)$ & \\
\hline History of diarrhea during pregnancy, n (\%) & $45(4.8)$ & $20(6.0)$ & $25(4.2)$ & .292 \\
\hline Negative rhesus factor, n (\%) & $23(2.5)$ & $9(2.8)$ & $14(2.3)$ & .900 \\
\hline Urine analysis positive result, $\mathrm{n}(\%)$ & $174(18.6)$ & $48(14.3)$ & $126(21.1)$ & .014 \\
\hline Stool examination positive result, $\mathrm{n}(\%)$ & $30(3.2)$ & $14(4.2)$ & $16(2.7)$ & .295 \\
\hline History of illness during pregnancy ${ }^{\mathrm{b}}, \mathrm{n}(\%)$ & $210(22.5)$ & $21(6.3)$ & $36(6.0)$ & 1.000 \\
\hline \multicolumn{5}{|l|}{ Food and dietary characteristics } \\
\hline Harvest volume in quintals, median (IQR) & $0.75(0-6)$ & $0(0-6.1)$ & $3(0-6)$ & $.217^{\mathrm{a}}$ \\
\hline Agrobiodiversity score, median (IQR) & $2(0-4)$ & $1(0-4)$ & $2(0-4)$ & $.027^{\mathrm{a}}$ \\
\hline Food insecure, n (\%) & $361(38.7)$ & $93(27.7)$ & $268(44.8)$ & $<.001$ \\
\hline Adequate dietary diversity score, $\mathrm{n}(\%)$ & $493(52.8)$ & $216(64.3)$ & $277(46.3)$ & $<.001$ \\
\hline Number of meals $\geq 3$ times per day, $n$ (\%) & $886(94.9)$ & $325(93.8)$ & $561(96.7)$ & .075 \\
\hline Fruits intake $\geq 3$ times per week, $n(\%)$ & $53(5.7)$ & $21(6.3)$ & $32(5.4)$ & .673 \\
\hline Vegetables intake $\geq 3$ times per week, $n(\%)$ & $86(9.2)$ & $34(10.1)$ & $52(8.7)$ & .546 \\
\hline Animal-source food intake $\geq 3$ times per week, $n(\%)$ & $230(24.6)$ & $83(24.7)$ & $147(24.6)$ & .967 \\
\hline Fasting, n (\%) & $650(69.6)$ & $209(62.2)$ & $441(73.7)$ & $<.001$ \\
\hline Alcohol intake $\geq 1$ times per week, $\mathrm{n}(\%)$ & $221(23.7)$ & $75(22.3)$ & $146(24.4)$ & .521 \\
\hline Coffee intake $\geq 1$ times per day, $n(\%)$ & $738(79.0)$ & $266(79.2)$ & $472(78.9)$ & .999 \\
\hline
\end{tabular}

${ }^{a}$ Mann-Whitney U-test, and ${ }^{\mathrm{b}}$ includes diarrheal diseases, malaria, sexually transmitted infections including HIV (human immunodeficiency virus), hepatitis and others

In the adjusted model, higher women empowerment, dietary diversity, pre-pregnancy BMI, and haemoglobin were associated with higher gestational weight gain. Additionally, adequate prenatal care was associated with higher gestational weight gain. Precisely, a women empowerment score above four (B 0.60, 95\% CI 0.06, 1.14) was positively associated with weight gain. Also, a U-shaped association between dietary diversity and weight gain was observed. A dietary diversity score below five $(\mathrm{B}-0.32,95 \% \mathrm{CI}-0.62,-0.03)$ was inversely related 
Table 4 Univariable and multivariable linear regression analysis of pre-conception and prenatal factors influencing gestational weight gain $(n=882)$, northern Ethiopia, 2018

\begin{tabular}{|c|c|c|c|c|}
\hline \multirow[t]{2}{*}{ Characteristics } & \multicolumn{4}{|c|}{ Effect on gestational weight gain in $\mathrm{kg}(95 \% \mathrm{Cl})$} \\
\hline & Unadjusted & $P$-value & Adjusted $^{\mathrm{b}}$ & $P$-value \\
\hline \multicolumn{5}{|l|}{ Model 1} \\
\hline Women empowerment score below 4 & $-0.53(-1.09,0.02)$ & .060 & $-0.48(-1.00,0.04)$ & .069 \\
\hline Women empowerment score above 4 & $0.96(0.39,1.53)$ & .001 & $0.60(0.06,1.14)$ & .028 \\
\hline Dietary diversity score below 5 & $-0.20(-0.52,0.11)$ & .208 & $-0.32(-0.62,-0.03)$ & .030 \\
\hline Dietary diversity score above 5 & $0.40(0.01,0.80)$ & .047 & $0.39(0.03,0.76)$ & .035 \\
\hline Food insecurity score & $-0.10(-0.13,-0.07)$ & $<.001$ & $-0.01(-0.05,0.02)$ & .438 \\
\hline Number of meals per day ${ }^{a}$ & $2.39(0.67,4.13)$ & .007 & $1.16(-0.57,2.88)$ & .189 \\
\hline Fruits intake (times per month) ${ }^{\mathrm{a}}$ & $0.82(0.39,1.24)$ & $<.001$ & $0.24(-0.28,0.77)$ & .364 \\
\hline Alcohol intake (times per month) ${ }^{\mathrm{a}}$ & $-0.71(-1.18,-0.23)$ & .004 & $-0.27(-0.73,0.19)$ & .256 \\
\hline Fasting, yes & $-0.59(-0.91,-0.26)$ & $<.001$ & $-0.13(-0.43,0.16)$ & .379 \\
\hline \multicolumn{5}{|l|}{ Perceived work burden } \\
\hline Easy & Reference & - & Reference & - \\
\hline Moderate & $-0.43(-0.75,-0.11)$ & .008 & $-0.26(-0.57,0.05)$ & .097 \\
\hline Difficult & $-0.36(-0.79,0.07)$ & .100 & $0.09(-0.37,0.55)$ & .700 \\
\hline \multicolumn{5}{|l|}{ Physical activity } \\
\hline Low & Reference & - & Reference & - \\
\hline Moderate & $-0.66(-0.96,-0.36)$ & $<.001$ & $-0.28(-0.60,0.04)$ & .085 \\
\hline High & $-0.76(-1.51,-0.01)$ & .046 & $-0.24(-1.00,0.51)$ & .529 \\
\hline Total distress score & $-0.17(-0.23,-0.12)$ & $<.001$ & $-0.003(-0.08,0.07)$ & .916 \\
\hline Total support score & $0.11(0.07,0.15)$ & $<.001$ & $0.02(-0.03,0.07)$ & .384 \\
\hline Intimate partner violence score & $-0.12(-0.16,-0.07)$ & $<.001$ & $-0.02(-0.07,0.04)$ & .559 \\
\hline Pre-pregnancy BMl in kg/m² & $0.43(0.35,0.51)$ & $<.001$ & $0.13(0.05,0.22)$ & .003 \\
\hline \multicolumn{5}{|l|}{ Husband occupation } \\
\hline Farmer & Reference & - & Reference & - \\
\hline Employed & $0.39(0.04,0.74)$ & .028 & $-0.17(-0.69,0.36)$ & .533 \\
\hline Daily laborer & $0.52(0.09,0.96)$ & .019 & $0.24(-0.27,0.74)$ & .353 \\
\hline Others & $0.03(-0.49,0.54)$ & .915 & $-0.27(-0.88,0.34)$ & .383 \\
\hline Household size & $-0.08(-0.16,-0.01)$ & .032 & $-0.003(-0.09,0.08)$ & .932 \\
\hline Model household, yes & $0.56(0.22,0.90)$ & .001 & $0.06(-0.26,0.38)$ & .701 \\
\hline Agrobiodiversity score ${ }^{\mathrm{a}}$ & $-0.49(-0.94,-0.03)$ & .036 & $0.04(-0.76,0.84)$ & .924 \\
\hline Number of stressful life events & $-0.27(-0.42,-0.11)$ & .001 & $-0.10(-0.24,0.05)$ & .184 \\
\hline \multicolumn{5}{|l|}{ Adequacy of prenatal care utilization } \\
\hline Inadequate & Reference & - & Reference & - \\
\hline Intermediate & $0.21(-0.27,0.70)$ & .387 & $0.07(-0.35,0.49)$ & .743 \\
\hline Adequate & $0.80(0.48,1.12)$ & $<.001$ & $0.58(0.28,0.88)$ & $<.001$ \\
\hline Adequate plus & $0.87(0.22,1.51)$ & .009 & $0.28(-0.29,0.86)$ & .334 \\
\hline Haemoglobin in $\mathrm{g} / \mathrm{dL}$ & $0.73(0.65,0.81)$ & $<.001$ & $0.54(0.45,0.64)$ & $<.001$ \\
\hline \multicolumn{5}{|l|}{ Model 2} \\
\hline \multicolumn{5}{|l|}{ Quartiles of pre-pregnancy BMI } \\
\hline First quartile $(\leq 18.31)$ & Reference & - & Reference & - \\
\hline Second quartile (18.32-19.48) & $0.67(0.26,1.07)$ & .001 & $0.13(-0.27,0.53)$ & .517 \\
\hline Third quartile (19.49-20.99) & $1.95(1.54,2.35)$ & $<.001$ & $0.71(0.24,1.17)$ & .003 \\
\hline Fourth quartile ( $\geq 21.00$ ) & $2.28(1.88,2.67)$ & $<.001$ & $0.77(0.27,1.27)$ & .003 \\
\hline
\end{tabular}

${ }^{a}$ log transformed, and ${ }^{b}$ regression coefficients and $95 \%$ confidence intervals are shown. Model 1 was additionally adjusted for gestational age at the time when weight was measured in the third trimester, and Model 2 was obtained by re-running model 1 after replacing pre-pregnancy BMI with quartiles 
to weight gain. In contrast, the association between dietary diversity score above five (B $0.39,95 \%$ CI $0.03,0.76$ ) and weight gain was positive. Moreover, higher pre-pregnancy BMI (B 0.13, 95\% CI 0.05, 0.22), higher haemoglobin (B 0.54, 95\% CI 0.45, 0.64) and adequate prenatal care (B $0.58,95 \%$ CI $0.28,0.88$ ) were linked with higher gestational weight gain. In total, the model explained $33.8 \%$ of the variation in weight gain.

As shown in Table 5, the results of marginal standardization show that optimizing women's economic empowerment, pre-pregnancy body mass index, dietary diversity, and adequate prenatal care would result in 50.1, $51.6,55.2$, and $41.4 \%$ probability of gaining adequate gestational weight, respectively.

Table 5 Results of marginal standardization showing the probability of gaining adequate gestational weight by optimizing the foremost prenatal and pre-conception factors as apparent in linear regression

\begin{tabular}{|c|c|}
\hline Characteristics & Probability, \% (95\% Cl) \\
\hline \multicolumn{2}{|c|}{ Economic empowerment score } \\
\hline$\leq 3^{\text {rd }}$ quartile & $43.1(37.5,48.6)$ \\
\hline $4^{\text {th }}$ quartile & $50.1(45.6,54.7)$ \\
\hline \multicolumn{2}{|c|}{ Socioeconomic empowerment score } \\
\hline$\leq 3^{\text {rd }}$ quartile & $46.7(41.8,51.6)$ \\
\hline $4^{\text {th }}$ quartile & $46.9(42.0,51.7)$ \\
\hline \multicolumn{2}{|c|}{ Experiencing intimate partner violence } \\
\hline Yes & $20.3(14.7,25.9)$ \\
\hline No & $26.6(22.3,30.9)$ \\
\hline \multicolumn{2}{|c|}{ Dietary diversity score } \\
\hline$\leq 3^{\text {rd }}$ quartile & $44.2(39.8,48.7)$ \\
\hline $4^{\text {th }}$ quartile & $55.2(45.3,65.2)$ \\
\hline \multicolumn{2}{|c|}{ Fasting for religious purposes } \\
\hline Yes & $32.2(29.1,35.3)$ \\
\hline No & $37.4(32.9,42.8)$ \\
\hline \multicolumn{2}{|c|}{ Pre-pregnancy body mass index } \\
\hline Underweight & $17.7(11.1,24.2)$ \\
\hline Normal weight & $51.6(47.8,55.4)$ \\
\hline \multicolumn{2}{|c|}{ Haemoglobin at prenatal care booking } \\
\hline$<11 \mathrm{~g} / \mathrm{dL}$ & $8.9(5.5,12.2)$ \\
\hline$\geq 11 \mathrm{~g} / \mathrm{dL}$ & $28.5(24.3,32.6)$ \\
\hline \multicolumn{2}{|c|}{ Adequate prenatal care utilization } \\
\hline Yes & $41.4(37.3,45.6)$ \\
\hline No & $36.5(32.8,40.2)$ \\
\hline \multicolumn{2}{|c|}{ Illness during the index pregnancy } \\
\hline Yes & $30.1(24.5,35.6)$ \\
\hline No & $38.7(35.3,42.0)$ \\
\hline \multicolumn{2}{|c|}{ Experiencing at least one stressful life event } \\
\hline Yes & $30.2(25.9,34.6)$ \\
\hline No & $34.3(30.3,38.2)$ \\
\hline
\end{tabular}

\section{Discussion}

In the present study, most women did not achieve adequate weight gain, primarily by those underweight before pregnancy. Women are missing both the pre-conception and pregnancy windows of opportunity with respect to improving maternal nutrition and optimizing maternal and child health. Higher women empowerment, dietary diversity, pre-pregnancy BMI, haemoglobin, and prenatal care were associated with higher gestational weight gain. The scientific evidence provided in this study indicated how the windows of opportunity could be used to improve maternal nutrition that could contribute to optimizing maternal and child health outcomes.

Our results on the prevalence of inadequate weight gain (64\%) accord with low-income countries [12, 13, $15,17,18]$, although slightly lower than in Harari, Ethiopia (69.3\%) [18]. Indeed, our results indicate that at the first measurement during pregnancy, there is already a relevant increase in body weight compared to a prepregnancy weight. This could merely justify the marginal incongruity with the study in Harari.

A unit increase in pre-pregnancy BMI was associated with higher gestational weight gain, aligning with the literature [18, 48, 49]. After replacing pre-pregnancy BMI with quartiles, only women in the third and fourth quartiles gained significantly higher weight. The association between higher pre-pregnancy BMI quartiles and higher weight gain implies that better nutritional status in the pre-conception period contributes considerably to maternal nutrition during pregnancy. This finding reflects the importance of paying due attention to the pre-pregnancy window. The insignificant weight gain among women with a lower quartile of pre-pregnancy BMI may also suggest that interventions during pregnancy may be too late for underweight women. Together, the findings may, therefore, highlight the benefit of starting public health interventions in the pre-conception period with a higher priority to underweight women to improve maternal nutrition. The interventions may include screening for undernutrition and considering multi-micronutrient supplements. Identifying and managing health problems that jeopardize maternal nutrition and nutritional education on dietary practices that affect intake and absorption of nutrients may also be relevant. For instance, coffee intake immediately before and/or after meals and fasting may impact dietary intake and absorption.

The association observed between pre-pregnancy BMI, and gestational weight gain may also suggest that the effectiveness of interventions targeting maternal nutrition during pregnancy depends largely on pre-pregnancy maternal nutritional status. However, our multivariable analyses revealed that other 
characteristics such as women's empowerment and diversity of maternal diet have an independent association with gestational weight gain.

In the present study, a unit increase in women empowerment score above four was associated with a substantial increase in gestational weight gain. We are not aware of any published research that assessed the influence of women's empowerment on weight gain, although some focused on related factors. Women empowerment reflects access to resources and decisionmaking power over resources and their own lives in and outside their households. Therefore, higher empowerment may imply better access to food, which can translate to improved dietary quality and maternal nutrition $[35,50-52]$. Hence, the finding indicates the importance of taking evidence-driven actions to empower women.

Our data also showed a U-shaped association between dietary diversity and gestational weight gain. Though no previous study showed such a U-shaped association, some studies in fact linked adequate dietary diversity and sufficient weight gain or the reverse [20, 53-55]. The inverse association between diversity of diet scores below five and weight gain may indicate that an increase in dietary diversity score may only be beneficial if it increases substantially, crossing the threshold score of 5 food groups. On the other hand, the positive association between dietary diversity scores above five and gestational weight gain may have been due to the nutrient adequacy containing higher energy and micronutrient required during pregnancy to attain the recommended weight gain [56]. Therefore, the association between dietary diversity and weight gain may provide an interesting point of attention in any actions that should focus on promoting dietary diversity of women regardless of other socio-economic circumstances.

Additionally, the positive association found between haemoglobin and gestational weight gain, as shown in Malawi [15], may also reflect the importance of promoting maternal dietary quality. Similarly, it may imply the need for strengthening the interventions already practiced like iron and folic acid supplementation and deworming. Conversely, as pregnancy advances, the increase in plasma volume may be followed by haemodilution leading to lower haemoglobin concentration which is opposite in direction to weight change at least until 35 to 38 weeks of gestation $[57,58]$.

In the present study, however, haemoglobin was measured at prenatal care booking, and the majority of the women gained inadequate weight. The time when haemoglobin was measured and the inadequate weight gain signify that the change in plasma volume and their prepregnancy nutritional status was low. Thus, the haemoglobin measures might be close to the early pregnancy state and indicate the nutritional condition of the women in early pregnancy. Moreover, a positive association was observed between adequate prenatal care and weight gain during pregnancy, as reported previously [59]. The association found between prenatal care and weight gain during pregnancy may also suggest that promoting access to and adequate use of prenatal care may be essential to improve maternal nutritional status.

Some major strengths of the study include using a population-based prospective design, assessment of preconception nutritional status, and detailed data collection to evaluate several nutrition-sensitive factors. The limitations of the study includes, for instance, that prepregnancy weight might have changed between the time of measurement and immediately before conception in some women. However, considering the weight measured before pregnancy is still better than the weight at the first prenatal care booking, which could be as far as 20 weeks into the pregnancy. In addition, the seasonal influence in dietary diversity was not well addressed, and haemoglobin was not adjusted for altitude. Finally, some of the variables assessed in our study were sensitive by nature, and our study might not have been free of social desirability bias.

\section{Conclusions}

Adequate gestational weight gain was not achieved by most women in the study area, primarily not by those who were underweight before pregnancy. Interventions that advance women's empowerment, dietary quality, pre-pregnancy nutritional status, and prenatal care utilization may improve gestational weight gain and contribute to optimizing maternal and child health outcomes.

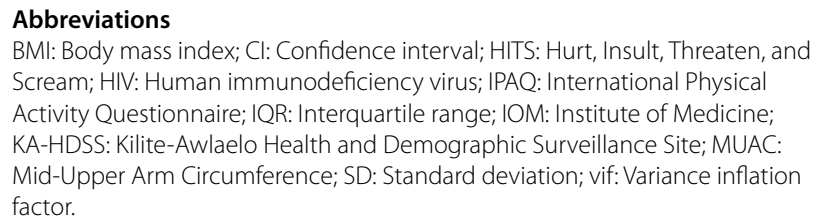

\section{Supplementary Information}

The online version contains supplementary material available at https://doi. org/10.1186/s12884-021-04171-z.

Additional file 1. Baseline characteristics of women who were and were not included in the complete-follow-up sample and final analysis, northern Ethiopia 2018.

\section{Acknowledgments}

Universities of Groningen, Aksum, and Mekelle, regional health bureau, district health offices, and Central Statistics Agency of Ethiopia are acknowledged for their valuable support. 


\section{Authors' contributions}

$\mathrm{KHM}, \mathrm{HG}, \mathrm{HMB}, \mathrm{EMvdB}$ and $\mathrm{AMB}$ involved in designing the study, data analysis and interpretation, and preparing the manuscript. $\mathrm{HG}, \mathrm{HMB}$, and $\mathrm{EMvdB}$ reviewed the manuscript. All authors read and approved the final manuscript.

\section{Funding}

No direct fund, although Universities of Aksum and Mekelle, Ethiopia supported the study in many ways.

\section{Availability of data and materials}

The data that supports the findings of this study are available from the corresponding author on reasonable request.

\section{Declarations}

\section{Ethics approval and consent to participate}

Institutional Research Review Board of College of Health Science, Aksum University, Ethiopia approved the study protocol [(ref. number: IRB 026/2017 dated 15/08/2017)]. Informed consent was obtained from participants. All methods were performed in accordance with the relevant guidelines and regulations (Declaration of Helsinki).

\section{Consent for publication}

Not applicable.

\section{Competing interests}

None declared.

\begin{abstract}
Author details
${ }^{1}$ Department of Public Health, University of Aksum, College of Health Sciences, Axum, Ethiopia. ${ }^{2}$ Department of Epidemiology, University Medical Center Groningen, University of Groningen, Groningen, The Netherlands. ${ }^{3}$ Department of Paediatrics, University Medical Center Groningen, University of Groningen, Groningen, The Netherlands. ${ }^{4}$ Department of Nutrition, University of Mekelle, Mekelle, Ethiopia.
\end{abstract}

Received: 16 April 2021 Accepted: 22 September 2021

Published online: 26 October 2021

\section{References}

1. American College of Obstetricians and Gynecologists. Committee opinion no. 549: obesity in pregnancy. Obstet Gynecol. 2013;121(1):213-7.

2. Rasmussen KM, Yaktine AL, editors. Institute of Medicine (US) and National Research Council (US) committee to reexamine IOM pregnancy weight guidelines. Weight gain during pregnancy: reexamining the guidelines. Washington (DC): National Academies Press (US); 2009.

3. Khan MN, Rahman MM, Shariff AA, Rahman MM, Rahman MS, Rahman MA. Maternal undernutrition and excessive body weight and risk of birth and health outcomes. Arch Public Heal. 2017;75:12.

4. Siega-Riz AM, Bodnar LM, Stotland NE, Stang J. The current understanding of gestational weight gain among women with obesity and the need for future research. NAM Perspectives. 2020;2020:10.31478/202001a.

5. Sommer C, Sletner L, Mørkrid K, Jenum AK, Birkeland KI. Effects of early pregnancy BMI, mid-gestational weight gain, glucose and lipid levels in pregnancy on offspring's birth weight and subcutaneous fat: a population-based cohort study. BMC Pregnancy Childbirth. 2015;15:84.

6. Huang A, Ji Z, Zhao W, Hu H, Yang Q, Chen D. Rate of gestational weight gain and preterm birth in relation to prepregnancy body mass indices and trimester: a follow-up study in China. Reprod Health. 2016;13(1):93.

7. Heude B, Thiébaugeorges O, Goua V, Forhan A, Kaminski M, Foliguet B, et al. Pre-pregnancy body mass index and weight gain during pregnancy: relations with gestational diabetes and hypertension, and birth outcomes. Matern Child Health J. 2012;16(2):355-63.

8. Drehmer M, Duncan BB, Kac G, Schmidt MI. Association of Second and Third Trimester Weight Gain in pregnancy with maternal and fetal outcomes. PLoS One. 2013:8(1):e54704.

9. Goldstein RF, Abell SK, Ranasinha S, Misso M, Boyle JA, Black MH, et al. Association of Gestational Weight Gain with Maternal and
Infant Outcomes: a systematic review and Meta-analysis. JAMA. 2017;317(21):2207-25.

10. El Rafei R, Abbas HA, Charafeddine L, Nakad P, Al Bizri A, Hamod D, et al. Association of pre-Pregnancy Body Mass Index and Gestational Weight Gain with preterm births and fetal size: an observational study from Lebanon. Paediatr Perinat Epidemiol. 2016;30(1):38-45.

11. Prendergast AJ, Humphrey JH. The stunting syndrome in developing countries. Paediatrics Int Child Health. 2014;34(4):250-65.

12. Asefa F, Cummins A, Dessie Y, Hayen A, Foureur M. Gestational weight gain and its effect on birth outcomes in sub-Saharan Africa: systematic review and meta-analysis. PLoS One. 2020;15(4):e0231889.

13. Wanyama R, Obai G, Odongo P, Kagawa MN, Baingana RK. Are women in Uganda gaining adequate gestational weight? A prospective study in low income urban Kampala. Reprod Health. 2018;15(1):160.

14. Hasan SMT, Rahman S, Locks LM, Rahman M, Hore SK, Saqeeb KN, et al. Magnitude and determinants of inadequate third-trimester weight gain in rural Bangladesh. PLoS One. 2018;13(4):e0196190.

15. Ouédraogo CT, Wessells KR, Young RR, Faye MT, Hess SY. Prevalence and determinants of gestational weight gain among pregnant women in Niger. Matern Child Nutr. 2020;16:e12887.

16. Young MF, Nguyen PH, Casanova IG, Addo OY, Tran LM, Nguyen S, et al. Role of maternal preconception nutrition on offspring growth and risk of stunting across the first 1000 days in Vietnam: a prospective cohort study PLoS One. 2018;13(8):e0203201.

17. Adu-Afarwuah S, Lartey A, Okronipa H, Ashorn P, Ashorn U, Zeilani M, et al Maternal supplementation with small-quantity lipid-based nutrient supplements compared with multiple micronutrients, but not with iron and folic acid, reduces the prevalence of low gestational weight gain in semiurban Ghana: a randomized controlled trial. J Nutr. 2017;147(4):697-705.

18. Asefa F, Nemomsa D. Gestational weight gain and its associated factors in Harari regional state: institution based cross-sectional study, Eastern Ethiopia. Reprod Health. 2016;13(1):101.

19. Desyibelew HD, Dadi AF. Burden and determinants of malnutrition among pregnant women in Africa : a systematic review and meta-analysis. PLoS One. 2019;14(9):e0221712.

20. Parker HW, Tovar A, McCurdy K, Vadiveloo M. Associations between prepregnancy BMI, gestational weight gain, and prenatal diet quality in a national sample. PLoS One. 2019:14(10):e0224034.

21. Hartley E, McPhie S, Skouteris H, Fuller-Tyszkiewicz M, Hill B. Psychosocial risk factors for excessive gestational weight gain: a systematic review. Women Birth. 2015;28(4):e99-109.

22. Kubo A, Ferrara A, Brown SD, Ehrlich SF, Tsai AL, Quesenberry CP, et al. Perceived psychosocial stress and gestational weight gain among women with gestational diabetes. PLoS One. 2017;12(3):e0174290.

23. Misgina KH, Boezen HM, van der Beek EM, Mulugeta A, Groen H. What factors are associated with pre-pregnancy nutritional status? Baseline analysis of the KITE cohort: a prospective study in northern Ethiopia. BMJ Open. 2021;11:e043484

24. Assefa Y, Gelaw YA, Hill PS, Taye BW, Van Damme W. Community health extension program of Ethiopia, 2003-2018: successes and challenges toward universal coverage for primary healthcare services. Glob Health. 2019;15(1):24

25. Assefa N, Berhane $Y$, Worku A. Wealth status, mid upper arm circumference (MUAC) and ante Natal Care (ANC) are determinants for low birth weight in Kersa, Ethiopia. PLoS One. 2012;7(6):e39957.

26. Zerfu TA, Umeta M, Baye K. Dietary diversity during pregnancy is associated with reduced risk of maternal anemia, preterm delivery, and low birth weight in a prospective cohort study in rural Ethiopia. Am J Clin Nutr. 2016;103(6):1482-8.

27. FAO \& FHI 360. Minimum dietary diversity for women: a guide to measurement. Rome; 2016

28. Coates J. Anne Swindale, Paula Bilinsky. Household Food Insecurity Access Scale (HFIAS) for measurement of household food access: indicator guide (v. 3). Washington, D.C.: Food and Nutrition Technical Assistance Project, Academy for Educational Development; 2007.

29. IPAQ Research Committee. The international physical activity questionnaire: short last 7 days self-administered format. 2002. http://www.ipaq.ki. se/.

30. Hjelm L, Mathiassen A, Miller D, and Wadhwa A. Creation of a Wealth Index. United Nations World Food Programme. 2017 
31. WHO/UNICEF Joint Monitoring Programme for Water Supply and Sanitation. Progress on sanitation and drinking water: 2010 update. Geneva: World Health Organization; 2010.

32. IPAQ Research Committee. Guidelines for Data Processing and Analysis of the International Physical Activity Questionnaire (IPAQ) — Short and Long Forms. 2005. https://docs.google.com/viewer?a=v\&pid=sites\&srcid= ZGVmYXVsdGRvbWFpbnx0aGVpcGFxfGd4OjEONDgxMDk3NDU1YW RIZTM.

33. Rabin RF, Jennings JM, Campbell JC, Bair-Merritt MH. Intimate partner violence screening tools. Am J Prev Med. 2009;36(5):439-445.e4.

34. Central Statistical Agency [Ethiopia] and ICF International. Ethiopia Demographic and Health Survey 2011. Addis Ababa, Ethiopia and Calverton, Maryland, USA: Central statistical agency and ICF International; 2012.

35. Alaofè H, Zhu M, Burney J, Naylor R, Douglas T. Association between Women's empowerment and maternal and child nutrition in Kalalé District of northern Benin. Food Nutr Bull. 2017;38(3):302-18.

36. Jennings $L, N a$ M, Cherewick M, Hindin M, Mullany B, Ahmed S. Women's empowerment and male involvement in antenatal care: analyses of demographic and health surveys (DHS) in selected African countries. BMC Pregnancy Childbirth. 2014;14:297.

37. Sibhatu KT, Qaim M. Farm production diversity and dietary quality: linkages and measurement issues. Food Sec. 2018;10:47-59.

38. Cheng ER, Rifas-Shiman SL, Perkins ME, Rich-Edwards JW, Gillman MW, Wright $R$, et al. The influence of antenatal partner support on pregnancy outcomes. J Women's Health. 2016;25(7):672-9.

39. Kocalevent RD, Berg L, Beutel ME, Hinz A, Zenger M, Härter M, et al. Social support in the general population: standardization of the Oslo social support scale (OSSS-3). BMC Psychol. 2018;6(1):31

40. Cox JL, Holden JM, Sagovsky R. Detection of postnatal depression. Development of the 10-item Edinburgh Postnatal Depression Scale. Br J Psychiatry. 1987:150:782-6.

41. Zigmond AS, Snaith RP. The hospital anxiety and depression scale. Acta Psychiatr Scand. 1983;67(6):361-70.

42. Karam F, Bérard A, Sheehy O, Huneau MC, Briggs G, Chambers C, et al. Reliability and validity of the 4-item perceived stress scale among pregnant women: results from the OTIS antidepressants study. Res Nurs Health. 2012;35(4):363-75

43. The Sphere. The Sphere Handbook: Humanitarian Charter and Minimum Standards in Humanitarian Response,fourth edition, Geneva, Switzerland, 2018.

44. Berntson J, Patel JS, Stewart JC. Number of recent stressful life events and incident cardiovascular disease: moderation by lifetime depressive disorder. J Psychosom Res. 2017;99:149-54.

45. Kotelchuck M. An evaluation of the Kessner adequacy of prenatal care index and a proposed adequacy of prenatal care utilization index. Am J Public Health. 1994;84(9):1414-20.

46. UCLA: Statistical Consulting Group. How can I run a piecewise regression in Stata?|Stata FAQ. https://stats.idre.ucla.edu/stata/faq/how-can-i-run-apiecewise-regression-in-stata/. Accessed 12 Oct 2021.
47. Muller CJ, Maclehose RF. Estimating predicted probabilities from logistic regression: different methods correspond to different target populations. Int J Epidemiol. 2014;43(3):962-70.

48. Suliga E, Rokita W, Adamczyk-Gruszka O, Pazera G, Cieśla E, Głuszek S. Factors associated with gestational weight gain: a cross-sectional survey. BMC Pregnancy Childbirth. 2018;18(1):465

49. Kheirouri S, Alizadeh M. The contribution of prenatal maternal factors to maternal gestational weight gain. Health Care Women Int. 2017:38(6):544-55.

50. Malapit HJL, Quisumbing AR. What dimensions of women's empowerment in agriculture matter for nutrition in Ghana? Food Policy. 2015;52:54-63.

51. Bosha T, Lambert C, Riedel S, Melesse A, Biesalski HK. Dietary diversity and anthropometric status of mother-child pairs from enset (false banana) staple areas: a panel evidence from southern Ethiopia. Int J Environ Res Public Health. 2019;16(12):2170.

52. Fox EL, Davis C, Downs SM, Schultink W, Fanzo J. Who is the woman in Women's nutrition? A narrative review of evidence and actions to support Women's nutrition throughout life. Curr Dev Nutr. 2019;3(1):nzy076

53. Tran NT, Nguyen LT, Berde Y, Low YL, Tey SL, Huynh DTT. Maternal nutritional adequacy and gestational weight gain and their associations with birth outcomes among Vietnamese women. BMC Pregnancy Childbirth. 2019;19(1):468

54. Wei $X$, He JR, Lin Y, Lu M, Zhou Q, Li S, et al. The influence of maternal dietary patterns on gestational weight gain: a large prospective cohort study in China. Nutrition. 2019;59:90-5.

55. Maugeri A, Barchitta M, Favara G, La Rosa MC, La MC, San Lio RM, et al. Maternal dietary patterns are associated with pre-pregnancy body mass index and gestational weight gain: results from the "mamma \& bambino" cohort. Nutrients. 2019;11(6):1308.

56. Hanson MA, Bardsley A, De-Regil LM, Moore SE, Oken E, Poston L, et al. The International Federation of Gynecology and Obstetrics (FIGO) recommendations on adolescent, preconception, and maternal nutrition: "Think Nutrition First". Int J Gynaecol Obstet. 2015;131(Suppl 4):S213-53.

57. Aguree S, Gernand AD. Plasma volume expansion across healthy pregnancy: a systematic review and meta-analysis of longitudinal studies. BMC Pregnancy Childbirth. 2019;19(1):508.

58. Jwa SC, Fujiwara T, Yamanobe Y, Kozuka K, Sago H. Changes in maternal hemoglobin during pregnancy and birth outcomes. BMC Pregnancy Childbirth. 2015;15:80.

59. Yeo S, Crandell JL, Jones-vessey K. Adequacy of prenatal care and gestational weight gain. J Women's Health. 2016;25(2):117-23.

\section{Publisher's Note}

Springer Nature remains neutral with regard to jurisdictional claims in published maps and institutional affiliations.

Ready to submit your research? Choose BMC and benefit from

- fast, convenient online submission

- thorough peer review by experienced researchers in your field

- rapid publication on acceptance

- support for research data, including large and complex data types

- gold Open Access which fosters wider collaboration and increased citations

- maximum visibility for your research: over 100M website views per year

At BMC, research is always in progress.

Learn more biomedcentral.com/submissions 